\title{
Study on the Development of Chinese Sugarcane Industry from the Perspective of the Industrial Integration
}

\author{
Fangfang Zeng, Chaozhi Zhu, Chuanfang Zheng* \\ Agricultural and Forestry Economic Management Post Doctoral Mobile Station/Jinshan College \\ Fujian Agriculture and Forestry University \\ Fuzhou, China
}

\begin{abstract}
Based on industrial integration theory, this study took the Chinese sugarcane industry as the research object, used AHP to construct the industry integration resource evaluation model. We selected 14 resource items that affect the integration of sugarcane industry as the evaluation index, used Delphi method to determine the weight of each. After analyzing, it is concluded that traditional cultivation techniques should be replaced by modern sugarcane science and technology, improving sugarcane comprehensive utilization level and developing sugarcane theme leisure tourism services and etc.
\end{abstract}

Keywords-industrial integration; sugarcane industry; АНP method; development

\section{INTRODUCTION}

Since 1970s, with the rapid development of information technology and industrial revolution, the developed countries have developed the phenomenon of intersecting and merging in the field of information industry. It aroused high attention and research of the academic and government departments, and gradually formed the theory of industrial integration. The research mainly focused on the connotation, type, motivation, and integration mechanism, degree of integration and fusion effect of industrial integration.

Since 2004, the issue of integration of agriculture and related industries has gradually become the focus of research in China. The mainly areas include the following aspects. Firstly, the explanation of the integration development of agriculture and related industries, mainly from two perspectives, the path evolution of agriculture industrialization and the motivation of the integration $^{[1]}$ (Yang, M. Q, 2004). Secondly, the academia put forward the definition of the integration and development of agriculture and related industries, emphasizing the goal of fusion or emphasizing the process of integration should be regard as typical ${ }^{[2]}$ (Fai, F. 2001). Thirdly, classified the integration of agriculture and related industries, the typical standard included intra industry integration and inter industry integration, different industrial forms of integration leads to kinds of integration $^{[3]}$ (Lei, D. T, 2000). Fourthly, analysis of the influence and effect on the traditional industrial organization theory from the view of integration, such as

Funded projects: Special funds of the Ministry of Agriculture and the Ministry of Finance, The Construction ofModern Agriculture (Sugarcane) Industry Technology System (CARS-20-11B); Fujian Agriculture and Forestry University's postdoctoralfund project, The Development of Sugarcane Industry in China under the Perspective of Public Policy (112/132300137).
$\mathrm{SCP}^{[4]}$ (HakilinF, 2005). Fifthly, countermeasures to promote the integration, mainly from the perspective of government, farmers and enterprises (Li, Y, 2017).

\section{OBJECTS AND METHODS}

\section{A. Objects}

With the expansion of the theory of industrial integration, it is used in a wider field of industrial economy ${ }^{[5]}$. In particular, the integration of agricultural industry prominently reflected in two aspects. Firstly, the boundary between the agricultural cultivation and the aquaculture is gradually blurred. According to the basic principle of the food chain, relying on the industry association in order to achieve internal integration, such as ecological agriculture and green agriculture. Secondly, the integration of the traditional agricultural production with the second and the third industries, such as developing leisure agriculture and rural tourism on the basis of the integration of agricultural production resources and agricultural leisure tourism function.

Therefore, in the research of the development of Chinese sugarcane industry, the study based on the basic idea of industrial integration, respectively analyzed sugarcane planting, sugarcane processing and sugarcane leisure tourism, put forward countermeasures to promote the integration and development of sugarcane industry.

\section{B. Methods}

\section{1) Selection of research methods}

In the process of the study on the development of sugarcane industry from the perspective of industrial integration, for one thing, there are many factors involved in the evaluation of industrial resources, how to select the factors appropriately directly influenced the scientificalness of the conclusion. For another, how to measure the weight of these factors is a key link in the quantitative research. There are two types of method that commonly used to determine the weight of evaluation factors at present. One is the subjective weighting method, which judging the relative importance of each evaluation index relative to the evaluation purpose by experts based on experience, and obtaining the index weight by comprehensive treatment, such as analytic hierarchy process(AHP) and Delphi 
evaluation method. The other is the objective weighting method, which automatic distribute the weight of each index according to certain rules, such as factor analysis, principal component analysis, entropy value determination and grey relational analysis. Among these methods, AHP is a qualitative and quantitative combined decision analysis method, especially suitable for processing multi-objectives, multi-levels and difficult to complete with quantitative methods of analysis and decision system engineering, is widely used in practical decision-making problems in complex evaluation system. After comparing the applicability of various methods, we used the AHP and Delphi together, intuitively solicited expert opinions, and analyzed them.

\section{2) Construction of index system}

The study construct a model for evaluating the resources of sugarcane industry, regarded the evaluation of the resources of the sugarcane industry as the target layer A, regarded primary industry, secondary industry and tertiary industry as element layer B1, B2 and B3, regarded 14 evaluation index as index layer $\mathrm{C}$.

Among the index that related to primary industry, natural environment(C1) index refers to natural environmental conditions, such as temperature, humidity, soil, and so on, which are related to the sugarcane, sugarcane planting area(C2) index refers to the survey and statistics of the planting area of the sugarcane annually, annual yield of fresh sugarcane(C3) index refers to the annual output of fresh sugarcane, technical level of sugarcane planting(C4) index refers to the sugarcane cultivation level of comprehensive cultivation measures, mechanical level of sugarcane planting(C5) index refers to the use, research and development of mechanical power equipment during the whole process of sugarcane planting. Among the index that related to secondary industry, sucrose annual yield (C6) index refers to the sugar yield of fresh sugarcane, which is mainly used to evaluate the primary processing capacity of sugarcane. Annual yield of sugarcane sugar by-products(C7) index, processing technology level of sugarcane product(C8) index and level of processing equipment for sugarcane products(C9) index, these three indexes assess the intensive processing capacity of sugarcane from three aspects of technology, equipment and products. The three indexes are mainly used to measure the level of comprehensive utilization and development of by-products in the production process of sucrose industry. There are five indexes that related to tertiary industry, included road transport service (C10) index, accommodation and catering industry (C11) index, wholesale and retail industry (C12) index, finance (C13) index and leisure tourism (C14) index. These indexes are used to evaluate the ability of departments of various services to optimize the allocation of resources in the primary and secondary industries.

\section{3) Determine the weight of the index}

After constructing the index system, we used AHP method and Delphi method to determine the importance of the factors in each index layer. We designed the questionnaire named Expert opinion consultation table for the weight distribution of the resources evaluation of the sugarcane industrial integration, selected 10 experts from the field of sugarcane and industrial integration, which came from the National Sugarcane Engineering and Technology Research Center, the national sugarcane industry system, Guangxi University and the Agricultural Scientific Research Institute of Guangxi Province and etc.. After multiple rounds of consultation, the judgment passed the consistency test, finally determined the weight of each index. As shown in TABLE I.

TABLE I. TABLE FOR THE WEIGHT DISTRIBUTION OF THE RESOURCES EVALUATION OF THE SUGARCANE INDUST RIAL INTEGRATION

\begin{tabular}{|c|c|c|c|c|c|}
\hline Target Layer A & Element Layer B & Weight & Index Layer C & Weight & Sequencing \\
\hline \multirow{14}{*}{$\begin{array}{l}\text { Resources Evaluation of the Sugarcane } \\
\text { Industrial Integration }\end{array}$} & \multirow{5}{*}{ Primary Industry } & \multirow{5}{*}{ 0. 1928} & Natural environment(C1) & 0.0367 & 10 \\
\hline & & & Sugarcane planting area(C2) & 0.0132 & 14 \\
\hline & & & Annual yield of fresh sugarcane(C3) & 0.0316 & 11 \\
\hline & & & Technical level of sugarcane planting(C4) & 0.0556 & 7 \\
\hline & & & Mechanical level of sugarcane planting(C5) & 0.0556 & 8 \\
\hline & \multirow{4}{*}{ Secondary Industry } & \multirow{4}{*}{0.5232} & Sucrose annual yield (C6) & 0.1241 & 3 \\
\hline & & & $\begin{array}{l}\text { Annual yield of sugarcane sugar by- } \\
\text { products(C7) }\end{array}$ & 0.0725 & 6 \\
\hline & & & $\begin{array}{l}\text { Processing technology level of sugarcane } \\
\text { product(C8) }\end{array}$ & 0. 1907 & 1 \\
\hline & & & $\begin{array}{l}\text { Level of processing equipment for sugarcane } \\
\text { products(C9) }\end{array}$ & 0.1359 & 2 \\
\hline & \multirow{5}{*}{ Tertiary Industry } & \multirow{5}{*}{0.2840} & Road transport service(C10) & 0.0888 & 5 \\
\hline & & & Accommodation and catering industry(C11) & 0.0428 & 9 \\
\hline & & & Wholesale and retail industry(C12) & 0.0303 & 12 \\
\hline & & & Finance(C13) & 0.0274 & 13 \\
\hline & & & Leisure tourism(C14) & 0.0947 & 4 \\
\hline
\end{tabular}

\section{RESULTS AND ANALYSIS}

After determining the weight of each index factor in the weight list of the sugarcane industry integration resources evaluation, We can see that secondary industry $(0.5232)>$ tertiary industry(0. 2840)> primary industry(0. 1928). Currently, planting sugarcane and processing into sucrose id the fundamental mission of the sugarcane industry, in the meantime, we should pay attention to the development of the tertiary industry, realize the integration of sugarcane production, processing and tourism services, in order to upgrade the comprehensive output value of the sugarcane industry. 


\section{A. Primary Industry resource elements are in the basic position}

The weight ratio of primary Industry resource elements is about 19 percent; we can see that it is an important basis for the integration and development of the sugarcane industry. In the dominant main producing area of sugarcane, there are 2 elements have important impact on the production capacity of sugarcane, one is technical level of sugarcane planting $(0$. 0556), the other is mechanical level of sugarcane planting ( 0 . 0556).

\section{B. Secondary Industry resource elements have decisive influence}

The weight ratio of secondary industry resource elements is about 52 percent, we can see that it has decisive influence on the integration and development of the sugarcane industry, especially processing technology level of sugarcane product(0. 1907)and level of processing equipment for sugarcane products (0.1359). At the same time, it should be noted that, the weight ranking of sucrose annual yield $(0.1241)$ is third in 14 related indexes. It means that sugarcane is the most important source of sugar in China, sugar processing ability directly affects the basic supply of sugar. In the process of sugarcane industrial integration, ensuring sucrose production is still an important goal. In addition, the weight ranking of annual yield of sugarcane sugar by-products $(0.0725)$ is sixth, we should pay attention to it.

\section{Tertiary industry resource elements play an important role in promotion}

The weight ratio of tertiary industry resource elements is about 28 percent; we can see that it plays an important role in promotion the sugarcane industry. Road transport service (0. 0888) and leisure tourism (0. 0947) should be paid more attention to. We should give priority to the region with better resource endowment in the tertiary industry; develop leisure tourism services on the basis of sugarcane planting and sucrose processing, so as to promote the integration and development of the primary industry, secondary industry and tertiary industry of sugarcane.

\section{COUNTERMEASURES}

\section{A. Replacing traditional cultivation techniques by modern sugarcane science and technology}

Chinese sugarcane producing areas are mainly concentrated in the Pearl River Delta, Guangdong, Hainan, Guangxi, Yunnan and Sichuan basins. The common problems in sugarcane planting are as follows. Firstly, because of the poor soil and a long period of continuous cropping, soil degradation, a large amount of fertilizer was applied in order to improve the yield of sugarcane. Secondly, due to small cultivated area, low culture level of farmers, lack of scientific fertilization knowledge, unscientific fertilization has led to the large amount of chemical fertilizer used, high cost of input, pollution of cultivated land and water in sugarcane production in China. The above problems are related to adapting to the variety selection of modern science and technology, reducing the high efficiency cultivation technology and using the medicine and fertilizer scientifically. Therefore, we must adopt modern cultivation technology to replace the traditional sugarcane cultivation, which featured with intensive cultivation and high input with low yield. Under the pressure of mechanization adaption and machine tool selection, we should adopt breeding species and light simplification of production management technology. We should select good breed to arrange the collocation layout covered early, middle and late maturing. We should return the filter mud of the sugar factory to the field, also the waste liquor of alcohol and the broken leaves after the harvest, in order to improve the soil nutrients continuously. We should adhere to the implementation of biological control and maintain good farmland ecological environment.

Matching with modern technology is the extension of the whole process of modern sugarcane machinery. At present, due to the small cultivated area and big drop of planting plot of sugarcane, the mechanical level of sugarcane planting in China is low. In the aspect of management, including field work, ditching, fertilizing, weeding, ridging and covering aspects, the technology of high efficiency and integration in field operation has not been realized due to incompatibility between agricultural machinery and farm implements. In general, the mechanization level of sugarcane in China is much lower than that in Australia, Brazil, the United States, India, Thailand and South Africa. Due to the poor site conditions and complex ecological types, we should pay attention to mechanization in line with local conditions through the combination of large and medium sized machinery, matching farm machinery and agricultural machinery with agronomy.

\section{B. Improving sugarcane comprehensive utilization level}

Currently, 95 percent of the sugarcane processing factory in China worked through sulphurous acid method to get sucrose. The method lags behind, sugarcane processing products is single, the by-products lack of diversity, and most of them are bagasse and molasses. In recent years, the global sugarcane industry has been affected by the constraints of resources and environmental problems. The most effective way to overcome difficulties and increase competitiveness is to increase the added value of sugarcane by-products and realize the diversification of products. Bagasse is the main by-product of sugarcane, which accounts for about 24 to 27 percent of the total quality of sugarcane. The compound enzyme preparation developed by biotechnology can effectively improve the efficiency of enzymatic hydrolysis of bagasse. There are rich bagasse resources in China, Approximately 24 million tons of bagasse can be produced annually (equivalent to 14 million 400 thousand tons of dry bagasse). Developing resources of byproducts from bagasse and converting them into high valueadded functional materials and biomass chemicals is an effective way to improve the technological level and competitiveness of sugarcane industry.

\section{Developing sugarcane theme leisure tourism services}

From the perspective of industrial integration, the development of tertiary industry is an important link to further enhance the comprehensive output value of the sugarcane industry. We should combine the sugarcane planting, processing and leisure tourism together ${ }^{[6]}$. Sugarcane could be grown into a variety of labyrinth styles, visitors could rest in the sugarcane field. We should design a number of nodes to 
introduce the knowledge of sugarcane growth, so as to let the tourists enhance the sense of learning. At the same time, we should develop the fruit cane planting to provide fresh food. The traditional sugarcane squeezing process should be developed into the project that allow tourism to experience the ancient French squeezing sugar pleasure, which includes squeezing the sugar cane juice, filtering bagasse, boiling sugarcane water, stirring the sugarcane syrup, airing the sucrose and etc.. At the same time, we should emphasize the comprehensive utilization technology of sugarcane for producing distilled liquor, such as rum and other production of distilled liquor from molasses. The processing process could be displayed and built into a sightseeing factory which has the value of industrial and tourism integration, so that visitors can intuitively experience the deep processing technology of sugarcane. Digging into sugarcane culture, encouraging sugarcane suitable planting area to develop sugarcane culture industry. We should systematically organized the knowledge of sugarcane planting, data processing technology of cane sugar and other sugarcane products and traditional folk art materials, so as to construct the sugarcane culture exhibition hall with local characteristics and the demonstration base for scientific research and education.

\section{SUMMARY}

In the process of sugarcane industrial integration, we need to stabilize the production of sugarcane as a prerequisite. That is because sucrose is the basic supply guarantee for sugar in China. It is a major strategic issue related to the national economy and the people's livelihood. On this basis, we could improve the comprehensive utilization level of sugarcane, and develop sugarcane theme leisure tourism, so as to enhance the comprehensive output value of sugarcane industry. The government, the enterprises and the farmers should work together to form a joint force to push to industrial integration. Among them, the government, as the maker of public policy and the guide of industrial convergence, should actively formulate relevant policies to encourage and promote industrial integration, support preferential policies in financial, land, technology and other aspects, excavate sugarcane culture and encourage the development of sugarcane culture industry. As a practitioner of sugarcane industry and an implementer of industrial integration, enterprises should enhance their cognition level of industrial integration value, strengthen technological innovation, extend industrial chain, enrich operation formats, cultivate cultural brand and enhance comprehensive strength of enterprises. As the most basic production unit of sugarcane industry, farmers should actively respond to the call of national industrial integration, and make rational use of farmland and homestead resources on the basis of sugarcane planting, so as to provide thematic leisure tourism services for sugarcane.

\section{ACKNOWLEDGMENT}

Thanks for the help from agricultural and forestry economic management post-doctoral mobile station of Fujian Agriculture and Forestry University, National Sugarcane Engineering and Technology Research Center, the national sugarcane industry system, Guangxi University and the Agricultural Scientific Research Institute of Guangxi Province and etc.

\section{REFERENCES}

[1] Yang, M. Q. Research on the correlation between industrial integration and industrial competitiveness. Decision and Statistics, 2004, vol. 10, pp. 92-96. (In Chinese)

[2] Fai, F. and Tunzelmann, V. N. Industry-Specific Competencies and Converging Technological Systems: Evidence from Patents Structural Change and Economics Dynamics. 2001. vol. 10, pp. 141-171.

[3] Lei, D. T, Industry Evolution and Competence Development: the Imperatives of Technological Convergence. International Journal of Technology Management. 2000. vol. 8, pp. 699-738

[4] HakilinF,. Niklas Adamsson, Christian Maxt, Margareta Norell. Design for Convergence: Managing Technological Partnerships and Competencies across and within industries. International Conference on Engineering Design ICED05: Melbourne, august, 2005:15-18.

[5] Liang, W. J. Research on the integration of China's agriculture and related industries from the perspective of industrial integration. Scientific and Economic Society, 2011, vol. 4, pp. 12-17. (In Chinese)

[6] Tang, S. Z. Development of leisure agricultural touris m resources in Henan Province based on the perspective of industrial integration. Agricultural resources and Regionalization in China, 2016, vol. 3, pp. 221-224. (In Chinese) 